\title{
Local Information in Foreign Exchange Markets
}

\author{
Lukas Menkhoff, University of Hannover, Germany \\ and \\ Maik Schmeling, University of Hannover, Germany
}

\author{
Discussion Paper 331 \\ April 2006 \\ ISSN: 0949-9962
}

\begin{abstract}
:
This study shows that order flow in a foreign exchange market only has permanent price impact if it comes from certain regions. These regions are - as predicted by the local information hypothesis centers of political and financial decision making. It is revealing that orders from other regions only show a very short-lived but no permanent price impact. Local information is so important that it carries over from the usually considered market orders to aggressively-priced limit orders too. The finding is robust to various market conditions, common news shocks and consideration of feedback trading.
\end{abstract}

JEL-Classification: F31, D82

Keywords: Local information hypothesis, price impact, limit orders, informed traders

For helpful comments we would like to thank participants at the FX microstructure workshop in Aix, the international conference on finance in Copenhagen, the BI/Norges Bank conference on the microstructure of equity and currency markets in Oslo and the annual conference of the German Economic Association in Bonn, in particular Geir Bjønnes, Michael Moore, Carol Osler and Erik Theissen. Leila Gadijeva provided most useful research assistance. We gratefully acknowledge financial support from the German Research Foundation (Deutsche Forschungsgemeinschaft DFG).

corresponding: Lukas Menkhoff, Department of Economics, University of Hannover, Königsworther Platz 1, D-30167 Hannover, Germany, menkhoff@gif.uni-hannover.de 


\section{Local Information in Foreign Exchange Markets}

\section{$1 \quad$ Introduction}

Due to the failure of the traditional macro approach in exchange rate modeling, early revealed by Meese and Rogoff (1983), the microstructure analysis of currency markets seems to provide new insights (see e.g. Frankel and Rose, 1995, Lyons, 2001, and Sarno and Taylor, 2002). In a sense, it reverses the conventional top down macro perspective by analyzing trader behavior bottom up. Assuming that market participants are asymmetrically informed, it seems worthwhile to analyze behavior at the microstructure level in order to better understand who has information and in which way this information gets into prices. One plausible source of information advantage according to the recent literature could be local proximity to centers of decision making. Obviously, an analysis testing the potential price impact of local information requires transaction data where currency orders can be linked to locations. This paper is the first, due to a new data set, that is able to examine this question exactly . We find strong evidence supporting the notion of local information advantage in foreign exchange markets.

The possible existence of local information advantages in financial markets does not seem to be self-evident in times of the internet and other modern instruments of communication. These instruments may nourish some skepticism and, indeed, enough studies demonstrate that investments in local assets are often based on home bias instead of an information advantage (e.g. Huberman, 2001). Nevertheless, the careful analysis of locally rooted information asymmetries has brought about overwhelming evidence during the last years that local information still exists, even in modern globalized markets. Coval and Moskowitz (2001) identify performance advantages of fund managers that invest in local firms, Hau (2001) shows that trading profits are higher for local equity traders, Ivković and Weisbenner (2005) find that local equity investments of individual investors earn higher risk-adjusted returns, Malloy (2005) demonstrates superior forecasting performance of analysts for firms within the analysts' region (see also Bae, Stulz and Tan, 2005, or Berger, Ehrmann and Fratzscher, 2006) and Portes and Rey (2005) can explain cross-border equity flows with distance-related informational frictions. So, local proximity to centers of decision making, such as firm headquarters, can provide an information advantage. 
In contrast to this strong evidence for equity markets, there is hardly any outright test of the local information hypothesis in foreign exchange. Peiers (1997) compares the quotes of single banks analyzing potential price leadership in the mark/dollar market around interventions of the Deutsche Bundesbank. She shows that at least one German bank seems to be better informed than others (but there is no such effect for US interventions according to Dominguez, 2003). De Jong et al. (2001) extend this work, among other things by considering more banks, and find a slight tendency but no unanimous proof of a local information hypothesis. Sapp (2002) identifies different price-leading banks in the European and the US market, again without a clear relation to the location of these banks' headquarters. Whereas these studies are actually interested in potential price leadership of single banks, Covrig and Melvin (2002) disaggregate the yen/dollar market into Japanese and other quotes and find that Japanese traders lead the market under certain circumstances. So there is some first evidence in favor of the local information hypothesis, but analyses are limited by the fact that they have to rely on indicative quotes which differ from prices (Daníelsson and Payne, 2002).

Therefore, it seems highly warranted to examine the hypothesis of a local information advantage in foreign exchange markets with better data. For this purpose, we can rely on the full record of orders in a modern electronic foreign exchange market, i.e. the Russian interbank Russian rouble - US dollar market. Fortunately, all orders can be linked unanimously to one of eight different regions in Russia. This allows a straightforward test of the local information hypothesis by applying the standard concept of price impact analysis (Hasbrouck, 1991, 2006). Accordingly, all kinds of microstructural effects, such as liquidity-induced price impacts, compensate each other and disappear over time - the only price impact that will be of permanent nature is due to information. As this concept is very well established in the literature it can be used as a reliable method to test the local information hypothesis: ${ }^{1}$ if there are regions which are better informed, trades from these regions should have a high permanent price impact whereas order flow from regions without any systematic information advantage should have a smaller permanent price impact or only temporary impacts on exchange rates due to liquidity effects.

Following the local information literature, regions are better informed when they host centers of decision making. In foreign exchange, this applies to two kinds of institutions: first, institutions that

\footnotetext{
${ }^{1}$ Applications to foreign exchange include Evans and Lyons (2002) or Payne (2003).
} 
generate or inform about public information, such as the central bank or ministries, and second, institutions that interpret public information better than others or that have access to private information from financial institutions by receiving their order flow (Lyons, 1997). ${ }^{2}$ In Russia, the political, financial and economic center is all in one place, i.e. Moscow. The only other region that can be considered as possibly better informed than the average is the country's second largest city, St. Petersburg. As orders reflect either the location of the trading bank or of its customer base, the local information hypothesis predicts that order flow from Moscow - possibly from St. Petersburg too - has more price impact than orders from Russia's periphery. Of course, there will be noise in the data as not every bank or its customers in Moscow will be better informed than others in the large country. However, this only heightens the stakes when testing the local information hypothesis.

At the core of our research, we find that only trades from the regions Moscow and St. Petersburg have permanent price impact in the Russian rouble - US dollar market, i.e. provide information. Trades from the other six Russian regions also show some short-lived price impact, which disappears, however, within a few minutes. This result provides strong evidence in favor of the local information hypothesis in foreign exchange markets. In fact, it is new evidence for foreign exchange markets based on trading data.

We further substantiate the importance of local information by considering limit orders, i.e. orders that are not executed immediately, for the first time in foreign exchange. Results show that not only the usually considered market orders (see e.g. Evans and Lyons, 2002, Payne, 2003) but also aggressively priced limit orders from both center regions provide information whereas those from other regions do not. Moreover, we show that findings are robust. They hold for various market conditions, they hold when we consider the possibility of common news shocks, i.e. a joint influence on order flow and prices, and they hold when we allow for feedback trading, i.e. influences from ongoing price changes on order flow.

Due to the new and detailed data being used here, this paper also provides evidence on related lines of recent research. First, it increases credence of the local information hypothesis in general because there has been no other study testing the local information hypothesis by the price impact ap-

\footnotetext{
${ }^{2}$ The order flow of foreign exchange trades does indeed show a very robust contemporaneous relation with exchange rates for the interbank market (e.g. Evans and Lyons, 2002, Payne, 2003), for single dealer order flow (e.g. Bjønnes and Rime, 2005), for customer order flow (e.g. Lyons, 2001, Evans and Lyons, 2005) and for financial customer order flow (Lyons, 2001, Marsh and O'Rourke, 2005, Osler, Mende and Menkhoff, 2006).
} 
proach, according to the best of our knowledge. Second, the new evidence highlights the importance of limit orders for information processing. It supports recent findings of an experimental study by Bloomfield, O'Hara and Saar (2005), findings for the US equity market studied by Kaniel and Liu (2004) and it motivates to disaggregate limit orders according to their economic purpose (see Hasbrouck and Saar, 2004). Third, the strong evidence on local information in foreign exchange markets supports the view that order flow indeed conveys information. ${ }^{3}$

This paper continues with a description of the market structure under consideration, data and descriptive statistics in Section 2. Section 3 analyzes price impacts of different regions and extends the analysis to different order types, common news shocks and feedback trading. Section 4 concludes.

\section{Market structure, data, and descriptive statistics}

\subsection{Market structure and dealing system}

The institutional structure of the Russian electronic FX interbank market is typical for a modern electronic market and has completely changed since June 29, 1999 (Goldberg and Tenorio, 1997, analyze an earlier market structure). Although volumes are low compared to leading currencies in the world, ${ }^{4}$ a very similar market structure and behavior seems to allow transfer of insights to other electronic currency and security markets.

The market is organized as a multiple dealer market without designated market makers or brokers. This electronic market is restricted to dealers who are located at one of the market's participating banks. Much trade is clearly driven by customer orders that are executed by the trading banks. We do not, however, have information about the motivation of trading but just observe the interbank market transactions.

The inter-dealer RUR/USD market we consider is based at the MICEX in Moscow. ${ }^{5}$ It plays a key role in Russia, since the official exchange rate to the US dollar is determined exclusively in this trading session. ${ }^{6}$ This means that the rouble price per unit USD that results from trading at the MICEX

\footnotetext{
${ }^{3}$ See for different approaches e.g. Ito, Lyons and Melvin (1998), Cheung and Wong (2000), Evans (2002), Osler (2003), Gehrig and Menkhoff (2004), Evans and Lyons (2005), Killeen, Lyons and Moore (2006), Dominguez and Panthaki (2006) and more critically Breedon and Vitale (2005).

${ }^{4}$ Trading in the Russian rouble (RUR) has a tiny but steadily increasing share of total turnover which amounts to $0.4 \%$ of total world currency trading volume (BIS, 2002, Table E.1.1).

${ }^{5}$ The MICEX is also the main Russian exchange for all kinds of financial assets such as equities and bonds.

${ }^{6}$ However, there occurred no intervention in our sample period.
} 
serves as the official country-wide rate to convert rouble into dollar. For this reason the country-wide trading at the MICEX we deal with is officially called the "unified trading session" (UTS).

During the time we consider in March 2002, trading took place only one hour a day from 10.30 to 11.30 Moscow time and the only instrument traded was the spot exchange rate. Nowadays, trading is prolonged to four hours per day and dealing also takes place in other instruments such as forwards.

Furthermore, there are eight regional currency exchanges based in the capitals of certain regions which also trade RUR/USD. ${ }^{7}$ These regional exchanges were opened for up to five hours (e.g. 9.3013.30 at the Moscow local exchange) a day in 2002. However, dealing at the regional exchanges occurs among bank dealers of the respective region only.

Trading in the UTS takes place on the electronic system SELT which is very similar to the systems of Reuters or the EBS consortium prevailing in major currency markets. ${ }^{8}$ SELT features only two order types, namely limit orders and cancellation orders. A limit order is an order to buy or sell a quantified US dollar volume to a pre-specified price or better, i.e. higher for selling and lower for buying orders. Submitted limit orders are stored in an electronic order book that has clear priority rules. Marketable limit orders are executed immediately against the best price available and are thus classified as market orders. ${ }^{9}$ If several limit orders on the same side of the book share an identical limit price, the earlier submitted limit order is executed. Cancellation orders may be used to cancel existing limit orders that have not yet been executed. Trading takes place anonymously, i.e. the details of a direct transaction are reported only to the participating traders.

However, the trading screen displays the cumulative buy and sell volume for the actual trading session and the last traded transaction (volume and price) and thus allows market participants to infer the volume and direction of the last trade(s). In addition - similar to the trading systems EBS or Reuters - the best bid and offer price plus respective volumes are given on the trading screen. Therefore, we distinguish between "ordinary limit orders", which are priced outside or at the best bid or ask (and thus line up in the order book invisible to the market) and aggressively priced limit orders, in short: "APL orders". The latter are placed within the prevailing spread and are thus directly visible on everybody's trading screen.

\footnotetext{
${ }^{7}$ The regions and some of their important characteristics are detailed in Section 2.4.

${ }^{8}$ SELT was in fact developed in cooperation with Reuters.
} 


\subsection{Data}

The analysis below employs a unique data set collected at the Russian inter-dealer market for RUR/USD over nine days in March 2002. Figure 1 plots this exchange rate showing price variance during trading periods and small jumps from day to day.

The data mirror the complete trading activity of this market, including all entered and deleted limit orders as well as market orders and a timestamp with a one second accuracy. Furthermore, we have the size of each trade. The market is populated by 722 traders who produce 38,442 observations, made up by 15,959 limit order entries, 8374 order deletions and 14,109 market orders. Total trading volume amounts to almost 700 mill. USD, i.e. about 78 mill. USD per day. The initiator of a deal, i.e. whether it is buyer or seller initiated, is available from the data, so that we do not need to use a classification algorithm.

Most importantly, each event in the data set can be allocated to the region of the initiator and the counterparty respectively. This permits a regional grouping of trades and traders which is a major vehicle for our analyses and, to the best of our knowledge, unique for an electronic currency market.

From the raw data we construct an event time data set that contains the midquote, a signed transaction indicator, signed transaction volume, the inside spread, aggregate buy and sell volume queued in the order book, the number of buy and sell limit orders outstanding and several measures of entered limit order flows which we detail later. Furthermore, the same series is also sampled at a frequency of thirty seconds to eliminate some of the microstructure noise associated with tick data.

\subsection{Descriptive statistics}

Intraday dynamics of this foreign exchange market follow diurnality patterns that are well in line with previous studies concerning electronic order markets in currency (see e.g. Payne, 2003) and stock markets (see e.g. Chung, van Ness and van Ness, 1999).

Table 1, Panel A presents descriptive statistics on the evolution of the order book and order size over the UTS for non-overlapping five minute intervals. When measured by the number of ask and bid

\footnotetext{
${ }^{9}$ Payne (2003, p. 312) also classifies crossing limit-orders as market orders, though the trading system Reuters D2000-2 analyzed there contains a pure "market order" type. Hasbrouck and Saar (2004) analyze a similar trading system as we do and use the same classification.
} 
orders outstanding we get an inverted U-shaped pattern which is less pronounced for volume outstanding. This should be due to the fact that our market does not trade continuously but only for one hour per day so that customer orders pile up until market opening. When the market opens the order book fills very quickly within the first minute to a high level of volume on both sides of the book. It seems to be a consequence that some activity figures, such as volume traded (i.e. the sum of market orders in an interval), tend to fall over time. The same was also found for electronic currency markets in Tokyo operating on EBS (Ito and Hashimoto, 2004). Despite this fact, the spread shows the expected U-shaped pattern.

Panel B of Table 1 shows return statistics for midquote changes, also calculated over five minute intervals. We find the typical unconditional means of nearly zero for midquote returns and a strong and significant autocorrelation in first moments. The variance is highest at the beginning and at the end of the UTS, which gives rise to the typical intraday pattern in return volatility. As expected, midquote returns are also heavily fat-tailed. Lastly, midquote return residual variance is serially correlated.

So the main difference between this market and others is its lower volume, both in trade and order book size, which corresponds to the smaller Russian economy. ${ }^{10}$ While e.g. Payne (2003) finds a mean transaction size of roughly 1.7 mill. USD in the DEM/USD market the Russian market has an average order size of 0.05 mill. USD. It seems noteworthy from this perspective that the mean of quoted spreads amounts to about 17 pips (one hundredth of a percent). Given an average midquote of about 31 RUR/USD the percentage spread is low when compared to other foreign exchange markets. ${ }^{11}$

\subsection{Characteristics of regions}

Next, we focus on the local information hypothesis by grouping orders according to their origin from eight regions in Russia. The most useful cut is between orders from the center regions Moscow and St. Petersburg versus orders from the six other non-center regions. Accordingly, we call orders originating from the centers "C-orders", their trades "C-trades", their traders "C-traders" and the others "NC-orders" etc. ${ }^{12}$

\footnotetext{
${ }^{10}$ Russian GDP was 345.6 bn. USD in 2002, and 10,400 bn. USD for the United States. Thus, Russia's economy was one thirtieth the size of the latter.

${ }^{11}$ Interbank spread in the most liquid USD/EUR market is 1 or 2 pips but this has to be put in relation to an exchange rate of about 1 . From this perspective, the Russian spread is low.

${ }^{12}$ This reliance on an ex ante characteristic is an advantage because many studies that are interested in information differences have to rely on ex post identification, so that trades are classified as informed that have been
} 
We present financial and economic characteristics of the eight regions differentiated by Russian statistics in Table 2. Russia's centers in terms of concentration of decision makers are Moscow, the capital city, and St. Petersburg. These two regions are also the financial centers, as several indicators in Table 2 show. Moscow has the highest number of, the largest and the most profitable banks in the country. Moreover, Moscow also takes the lead in international orientation, as its banks have the highest customer foreign currency account volume in absolute and relative terms. St. Petersburg ranks second in all of these categories in Russia. In contrast to these financial indicators, industrial production as a proxy of economic activity is more evenly distributed among the eight regions. Thus, Moscow and St. Petersburg significantly outweigh the other six regions in absolute financial size, in financial outward orientation and in further ratios indicating a financial center.

If there is any local information concerning exchange rates in Russia it will be concentrated in the two center regions - and thus among the C-orders - as argued above. ${ }^{13}$ Of course, there will be also liquidity trades in the center regions and possibly informed trades in the non-center, peripheral regions which makes our measure of information imprecise. As a consequence, we cannot expect clear-cut results as in an experimental situation (see Bloomfield, O'Hara and Saar, 2005). If, however, our necessarily imprecise distinction between more and less informed orders yields a plausible outcome, the result would seem to be even more credible.

As a final prerequisite for the following analysis we provide additional details about $\mathrm{C}$ - and $\mathrm{NC}$ traders in Table 3. C-traders are $64 \%$ of the population, traders from Moscow alone have a share of $47 \%$. Table 3 also gives average volumes for each of the three order types - i.e. market, APL and ordinary limit orders - and trading profits. According to Easley and O'Hara (1987) one may expect that informed trade is related to larger order size. Indeed, we find that traders from the two center regions trade and submit higher volumes as measured per trader and per event over the nine trading days.

Moreover, one would expect that traders from center regions earn higher profits. Due to our data, however, profit calculation has three limitations: first, information is restricted to earnings and not to costs, second, we do not know inventories and third, we only know the interbanking leg of

identified through some sort of data-based algorithm (see e.g. the discussion in Campbell, Ramadorai and Vuolteenaho, 2005).

${ }^{13}$ It seems plausible ex ante that information on financial prices is concentrated in financial centers. This relation is supported by some studies in foreign exchange finding that financial customer orders are informative in contrast to orders from commercial customers (e.g. Lyons, 2001, Marsh and O’Rourke, 2005, Osler, Mende and Menkhoff, 2006). 
transactions but have no information about the customer leg. So calculations are indicative at best. Assuming that trading banks would keep eventual inventories arising from trading at the UTS until the next day, we calculate the profit figures. From Table 3 the relative higher profitability of C-versus NC-traders becomes obvious.

Table 3 also shows, unexpectedly so from traditional microstructure theory, that C-traders also extensively use limit orders and that NC-traders also make heavy use of market orders. Furthermore, about one quarter of limit orders are priced aggressively. These APL orders are particularly interesting since they have much higher fill rates. Whereas APL orders are filled by about $75 \%$, only $45 \%$ of ordinary limit orders are filled. The traditional argument against the use of limit orders by informed traders is the fact that their execution is not guaranteed. So why should informed traders risk nonexecution when they are able to capitalize on their information via market orders? A natural answer is that limit orders are cheaper. Accordingly, it is intuitive to assume that informed traders use APL orders to improve their probability of execution while avoiding payment of the full market spread. In this trade-off between immediacy and costs APL orders obviously stand between market orders and ordinary limit orders.

To underscore this idea let us look at the speed of order execution, i.e. survival probabilities of aggressively priced and ordinary limit orders for C- and NC-traders (Appendix 1). The analysis has a clear message: APL orders are executed faster than ordinary limit orders and APL orders that are not executed are cancelled faster than respective ordinary limit orders.

\section{$3 \quad$ Price impact of regional groups}

In this section we examine the price impact of order flow on returns and show that it significantly differs for C- versus NC-traders. Due to the more disaggregated data we use, the standard VARframework needs some adjustment, which is motivated in Section 3.1. The application in Section 3.2 provides the main results which are controlled by further structural VARs in Section 3.3.

\subsection{Econometric approach}

To measure the long-run impact of market and limit order flow shocks on spot midquotes we use vector autoregressions, which have been successfully applied in several microstructure settings and serve as a tool to test for informed trading. While Hasbrouck (1991) and Payne (2003) use a struc- 
tural VAR (SVAR) to explicitly account for the influence of market order flow on returns, Brandt and Kavajecz (2004) use a restricted VAR in the sense that they regress bond yields on past common factors to get a more parsimonious structure. As a reference for our work we briefly review the approach of Payne (2003), which is an application of Hasbrouck (1991). A bivariate SVAR is employed

$$
A y_{t}=\left(\begin{array}{cc}
1 & -\alpha_{1} \\
0 & 1
\end{array}\right)\left(\begin{array}{l}
r_{t} \\
x_{t}
\end{array}\right)=\Gamma(L) y_{t}+B \varepsilon_{t}
$$

where $\Gamma(\mathrm{L})$ is a matrix polynomial in the lag operator and the structural assumption is contained in the upper right element of the A matrix, namely that (market) order flow $x_{t}$ causes midquote returns $r_{t}$. $B$ is a diagonal matrix and the structural shocks $\varepsilon_{\mathrm{t}}$ are assumed to be mutually and serially uncorrelated at all leads and lags with unit variances. Inverting the system yields the VMA representation, which can be used for computing impulse-responses and variance decompositions. As a comparison, we use this approach to compute the cumulative impulse-response of midquote returns to a one standard deviation shock in market order flow (see the resulting figure in Appendix 2) ${ }^{14}$ The cumulative response of returns to order flow shocks in the RUR/USD market shows the usual shape (see e.g. Hasbrouck 1991 or Payne 2003 for comparison) and the price equation has an $\mathrm{R}^{2}$ of about $12 \%$.

However, since we are dealing with five variables (returns and four flows) it is not possible to apply this setup directly . Therefore, our approach is twofold: we first employ a reduced form VAR since a priori there is little theoretical guidance on the interrelations of returns, limit and market order flows of different trader groups. Second, in Section 3.3, we employ SVARs with different identifying assumptions to check whether results obtained so far are robust to common news shocks (Evans and Lyons, 2003) and feedback trading (Daníelsson and Love, 2006). Moreover, as mentioned before, we opt to minimize the exposure to noise in our data by aggregating our tick-by-tick data into (nonoverlapping) intervals of thirty seconds.

Since we are interested in price impacts of both market and APL orders and the interrelations of different order types, we construct order flow variables for both order types. Market order flow is measured the standard way: buyer initiated trades occurring at the ask are coded as positive whereas seller initiated trades occurring at the bid are coded as the negative of the trade size. In the case of

\footnotetext{
${ }^{14} \mathrm{We}$ do not report further results for the sake of brevity but they are available upon request.
} 
APL orders, a bid is coded as the positive of the submitted volume whereas ask side orders are coded as the negative of the submitted volume. ${ }^{15}$

We employ the following five variables in our VAR: the midquote return in percent (r), market order flow of $\mathrm{C}-\left(\mathrm{x}^{\mathrm{C}}\right)$ and $\mathrm{NC}$ - traders $\left(\mathrm{x}^{\mathrm{NC}}\right)$ as well as APL order flow of $\mathrm{C}-\left(\mathrm{s}^{\mathrm{C}}\right)$ and NC-traders $\left(\mathrm{s}^{\mathrm{NC}}\right)$.

\subsection{Reduced form VARs}

This section reports results from reduced form VARs with midquote returns and all four flow variables. We find that both flow variables of C-traders have a significant and permanent effect on midquotes whereas flows of NC-traders only have transitory price impact.

In order to measure the impact of order flows on midquote returns we employ the following reduced form VAR

$$
y_{t}=\left(\begin{array}{lllll}
r_{t} & x_{t}^{C} & x_{t}^{N C} & s_{t}^{C} & s_{t}^{N C}
\end{array}\right)^{T}=\Gamma(L) y_{t}+v_{t}
$$

where $\Gamma(\mathrm{L})$ is the usual matrix polynomial in the lag operator and $v_{t}$ is a $(5 \times 1)$ vector of shocks. The above representation can be inverted to obtain responses of the dependent variables after a shock in $v_{t}$ (see e.g. Lütkepohl, 2005). Estimation proceeds via OLS and we employ a bootstrap with 200 replications throughout the following analyses to obtain standard errors for the impulse-responses. Impulseresponses themselves are generalized impulse-responses which do not depend on the ordering of the variables since orthogonalization of shocks is not necessary in this framework (Pesaran and Shin, 1998).

The system in (2) is clearly a reduced form of possibly complicated microstructural effects that determine the dynamic interplay between two different groups and flows of two different forms of orders. Therefore, results obtained from (2) are used as a benchmark which can be compared to the results from structural models employed in the next section. However, since structural assumptions are subject to the judgment of the researcher it seems useful to have a more unbiased benchmark like the one presented here.

As a first useful exercise, we plot cumulative impulse-responses of midquote returns to a one standard deviation shock in each of the four flow variables in Figure 2. As can be inferred, both market and APL flows of informed traders have a significant and permanent long-run impact on mid-

\footnotetext{
${ }^{15}$ Many studies (e.g. Bjønnes and Rime, 2005) use signed transaction indicators. Our results obtained for signed
} 
quotes, which is consistent with information effects (Hasbrouck, 1991). Furthermore, the price impact of about $0.0016 \%$, i.e. 16 pips, for a one standard deviation shock in the market order flow of Ctraders translates into a permanent effect on the midquote of about 5 pips. Given an average halfspread of about 8.5 pips, one may conclude that nearly $60 \%$ of the spread compensate for asymmetric information. This figure is virtually identical to the one found in Payne (2003). Both NC-traders' flows do not have this significant permanent impact. ${ }^{16}$ More specifically, NC-traders' market order flows $\left(\mathrm{x}^{\mathrm{NC}}\right)$ and APL order flow $\left(\mathrm{s}^{\mathrm{NC}}\right)$ only have transitory price impact which is consistent with a liquidity effect but not with informed trade (Hasbrouck, 1991). ${ }^{17}$

How can these findings be interpreted? First, the fact that both order types are informative for future price movements underscores recent findings in the literature (e.g. Kaniel and Liu, 2004) that at least certain limit orders carry information for future price movements. Second, the finding that both order types have a permanent price impact strengthens the finding of Hasbrouck and Saar (2004) that certain kinds of limit orders are closer substitutes to market orders than to traditional, liquidity supplying limit orders.

In order to check our results for robustness and plausibility, we also run VARs on four subsamples sorted by the time of the trading session, i.e. we estimate the VAR on the first fifteen minutes of the trading sessions, then on minutes 16 to 30 and so on. Results are given in Table 4, Panel A. The price impacts vary with the time of the day but the general result is unchanged, i.e. both C-traders' flows have a significant permanent effect in midquotes whereas NC-traders' flows do not. The $\mathrm{R}^{2} \mathrm{~s}$ for the reduced form VARs are quite high, ranging from $8 \%$ to about $20 \%$. Joint tests for autocorrelation up to the tenth lag do not indicate significant serial correlation in the residual series. Panel B reports residual autocorrelation in the upper triangular part along with respective p-values in the lower triangular part. Obviously, there is significant contemporaneous correlation between midquote returns and each of the flows' residuals which will be discussed further in the next section.

Finally, we also condition our price impact analyses on variables that reflect certain market conditions typically found to be important in microstructure analysis. We use transacted volume as a

\footnotetext{
volume of flows are qualitatively unchanged if we use signed transaction indicators instead.

${ }^{16}$ For the graphical expositions we truncate the cumulative impulse responses at a horizon of 10 (i.e. five minutes) after which they stay flat. Results on long-run impacts shown in tables are exact numbers obtained analytically (see Lütkepohl, 2005).

${ }^{17}$ As a robustness exercise (not shown here), using also ordinary limit order flows does not yield significant price impacts for both trader groups.
} 
proxy for market activity, order book volume as a measure of market liquidity and spreads to reflect the degree of asymmetric information. Each variable is calculated for a given interval of thirty seconds. Moreover, these variables are detrended to eliminate typical intraday patterns and thus to rule out the indirect influence of time. ${ }^{18}$ Figure 3 plots price impacts of C-traders sorted by high and low trading volume (TV), order book volume (BV) and spreads, respectively.

As can be seen from Figure 3, price impacts for both market and APL orders vary markedly in the sub-samples. Interestingly, APL and market orders' price impacts vary in the same direction, which underscores the idea that both are close substitutes. Furthermore, results for both order flows are consistent with standard microstructure theory: first, consider price impacts and trading activity. Our results are consistent with the empirical findings of Dufour and Engle (2000) that market activity boosts the size of quote revisions. Results also confirm the theory of Foster and Viswanathan (1990), who model high volume as a result of informed trading, which deters the uninformed from trading and also comply with the "Mixture of Distribution Hypothesis" (Clark, 1973) which posits that trading volume and return variance are both driven by an unobservable factor related to news diffusion. Therefore, higher price impact during intervals of higher trading activity is consistent with informed trade. Second, the positive relation between spreads and price impacts is intuitive since higher bid-ask spreads are thought of as compensating for adverse selection risk (see e.g. Easley and O'Hara, 1987). Higher spreads then imply a higher probability of informed trade and therefore higher price impacts. Finally, higher liquidity supply as measured by the size of the order book naturally alleviates the price impact of trades. The same is found in Payne (2003).

To further check the robustness of our main findings, we conduct price impact analyses in two more settings.

\subsection{Structural VAR analysis, common news shocks and feedback trading}

This section extends the reduced form VAR to structural VARs to account for effects recently discussed in the literature, namely common news shocks (Evans and Lyons, 2003) and feedback trading (Evans and Lyons, 2003, Daníelsson and Love, 2006). As was seen in Table 4, Panel B, there is

\footnotetext{
${ }^{18}$ Specifically, we regress each of the sorting variables on 60 time dummies representing the minute of the trading session. We then use the fitted values of this regression as the typical intraday pattern and divide the actual observations by the fitted value of the corresponding minute. We run this procedure on our tick-by-tick data set and aggregate to the one-minute interval used here afterwards.
} 
significant residual correlation which may be used to identify structural parameters associated with these two concepts.

First, we employ a structural VAR of the following form

$$
\mathrm{Ay}_{\mathrm{t}}=\Gamma(\mathrm{L}) \mathrm{y}_{\mathrm{t}}+\mathrm{B} \zeta_{\mathrm{t}}
$$

where

$$
\begin{aligned}
\mathrm{Ay}_{\mathrm{t}} & =\left(\begin{array}{ccccc}
1 & -\alpha^{\mathrm{x}, \mathrm{C}} & -\alpha^{\mathrm{x}, \mathrm{NC}} & -\alpha^{\mathrm{s}, \mathrm{C}} & -\alpha^{\mathrm{s}, \mathrm{NC}} \\
0 & 1 & 0 & 0 & 0 \\
0 & 0 & 1 & 0 & 0 \\
0 & 0 & 0 & 1 & 0 \\
0 & 0 & 0 & 0 & 1
\end{array}\right)\left(\begin{array}{c}
\mathrm{r}_{\mathrm{t}} \\
\mathrm{x}_{\mathrm{t}}^{\mathrm{C}} \\
\mathrm{x}_{\mathrm{t}}^{\mathrm{NC}} \\
\mathrm{s}_{\mathrm{t}}^{\mathrm{C}} \\
\mathrm{s}_{\mathrm{t}}^{\mathrm{NC}}
\end{array}\right) \\
\mathrm{B} \zeta_{\mathrm{t}} & =\left(\begin{array}{ccccc}
\beta^{\mathrm{r}} & 0 & 0 & 0 & 0 \\
\delta^{\mathrm{x}, \mathrm{C}} & \beta^{\mathrm{x}, \mathrm{C}} & 0 & 0 & 0 \\
\delta^{\mathrm{x}, \mathrm{NC}} & 0 & \beta^{\mathrm{x}, \mathrm{NC}} & 0 & 0 \\
\delta^{\mathrm{s}, \mathrm{C}} & 0 & 0 & \beta^{\mathrm{s}, \mathrm{C}} & 0 \\
\delta^{\mathrm{s}, \mathrm{NC}} & 0 & 0 & 0 & \beta^{\mathrm{s}, \mathrm{NC}}
\end{array}\right)\left(\begin{array}{c}
\zeta_{t}^{\mathrm{r}} \\
\zeta_{t}^{\mathrm{x}, \mathrm{C}} \\
\zeta_{t}^{\mathrm{x}, \mathrm{NC}} \\
\zeta_{t}^{\mathrm{s}, \mathrm{C}} \\
\zeta_{t}^{\mathrm{s}, \mathrm{NC}}
\end{array}\right)
\end{aligned}
$$

and $\Gamma(\mathrm{L})$ is again a matrix in lag polynomials. The vector of residuals $\zeta_{t}$ has variance $\operatorname{Var}\left[\zeta_{t}\right]=\mathrm{I}_{5}$ where $\mathrm{I}_{\mathrm{n}}$ is the $\mathrm{n}$-dimensional identity matrix. The structural parameters $\delta^{\mathrm{x}, \mathrm{C}}, \delta^{\mathrm{x}, \mathrm{NC}}, \delta^{\mathrm{s}, \mathrm{C}}, \delta^{\mathrm{s}, \mathrm{NC}}$ capture the effect of shocks in midquote returns $r_{t}$ on the four flow variables. Therefore, news that affect the midquote might instantaneously spill over to order flows and induce orders that are not due to private information about customer order flows. Also note that the system is overidentified with two degrees of freedom.

Again, we first plot cumulative impulse-responses for this system in Figure 4. As can be seen, the results obtained so far are robust to allowing spillovers from return shocks to order flow shocks. NC-traders' flows still only have transitory price impact (market orders) or no significant impact at all (APL orders). More detailed results are shown in Table 5, Panel A. According to the first row, the sum of coefficient estimates for lagged order flows is only significantly positive for flows of C-traders. The same is true for the analytical cumulative impulse-responses shown in the second column. The forecast variance decompositions show that $38 \%$ of the explained variance comes from C-traders' market order flow and that more than 9\% comes from APL order flow of the same group. NC-traders make up for about $10 \%$ of explained variance in total. Finally, the $\chi^{2}$-test for overidentifying restrictions is not rejected and there is no evidence of autocorrelation in residuals. 
Moreover, the estimated direct price impact coefficients $\alpha^{\mathrm{i}}$ show that both flows from C-traders and market order flow from NC-traders are significantly positive. As discussed above, the latter seems to be a pure liquidity effect since there is no significant permanent impact on returns for NC-traders' market order flow. Interestingly, the spillover coefficients $\delta^{\mathrm{i}}$ are significantly negative for market orders and not significant for APL-orders. Looking at the sizes of the spillover coefficients, however, the reaction of C-traders on common news is several times larger than that of NC-traders, suggesting that common news shocks are more pronouncedly processed by C-traders.

As a second exercise, we introduce feedback trading by C-traders to the SVAR while still allowing for the influence of common news on order flows. Since the system specified in (4) leaves two degrees of freedom, we have to restrict ourselves to two feedback trading coefficients. We allow contemporaneous returns to influence both order flows of C-traders only because these traders are more active and might thus pursue feedback trading strategies. Furthermore, these traders are the only ones who have a significant price impact so it would be more interesting to see whether their permanent price impact vanishes when accounting for contemporaneous feedback from returns to order flow. However, given the existing literature, this is not very likely. Evans and Lyons (2003) show that the feedback effect is rather negative than positive and Daníelsson and Love (2006) find feedback trading effects in VARs to be of little importance for aggregation intervals of up to one minute. However, in order to account for this possibility we modify the SVAR setup so that returns may have a direct impact on C-traders' order flow. This translates into

$$
\operatorname{Ay}_{t}=\left(\begin{array}{ccccc}
1 & -\alpha^{\mathrm{x}, \mathrm{C}} & -\alpha^{\mathrm{x}, \mathrm{NC}} & -\alpha^{\mathrm{s}, \mathrm{C}} & -\alpha^{\mathrm{s}, \mathrm{NC}} \\
-\psi^{\mathrm{x}, \mathrm{C}} & 1 & 0 & 0 & 0 \\
0 & 0 & 1 & 0 & 0 \\
-\psi^{\mathrm{s}, \mathrm{C}} & 0 & 0 & 1 & 0 \\
0 & 0 & 0 & 0 & 1
\end{array}\right)\left(\begin{array}{c}
\mathrm{r}_{\mathrm{t}} \\
\mathrm{x}_{\mathrm{t}}^{\mathrm{C}} \\
\mathrm{x}_{\mathrm{t}}^{\mathrm{NC}} \\
\mathrm{s}_{\mathrm{t}}^{\mathrm{C}} \\
\mathrm{s}_{\mathrm{t}}^{\mathrm{NC}}
\end{array}\right)
$$

where (4b) still applies and the two feedback coefficients are $\psi^{\mathrm{x}, \mathrm{C}}\left(\psi^{\mathrm{s}, \mathrm{C}}\right)$ for C-traders' market (APL) order flow.

Results for specification (5) are shown in Panel B of Table 5. The two feedback coefficients are not significantly different from zero, which might have been expected due to our relatively high sampling frequency of thirty seconds, as discussed above. Furthermore, results do not differ with respect to the overall conclusion that only C-traders' order flows have a significant long-run price impact. 
However, the variance decomposition reveals that in this specification each of the two order flows from C-traders account for an equal amount of $21 \%$ of the explained variance.

All in all, the analyses show that only orders from a center (C-orders) have permanent price impact. This can be interpreted as informed trade. Orders from the periphery of Russia (NC-orders) have transitory price impact at best, which might be explained by liquidity effects that are common to all orders hitting the market regardless of the information content.

\section{Conclusions}

This paper supports the hypothesis that information is asymmetrically distributed between locations in foreign exchange markets. As our standard method to infer about information, we use price impact analyses to determine whether orders have transitory or permanent impact (Hasbrouck, 2006). If prices change temporarily, this is interpreted as indicating market frictions, such as short-term liquidity shocks. If prices, however, do not reverse after a trade to the former level, information is conveyed.

The local information hypothesis states that information may be asymmetrically distributed between different regions. Those locations which are close to centers of decision making are potentially better informed, whereas peripheral locations are expected to be rather less informed. In the Russian rouble - dollar market under review, locations being close to decision makers should be in the region of Moscow and possibly the region of St. Petersburg, the center regions. Orders from the six other regions, being quite different from the two centers according to the Russian geographical statistics should be less informed on average. Fortunately, the data set of nine days country-wide interbank RUR/USD trading allows allocating orders to eight regions each. Accordingly, the local information hypothesis can be tested with exact trading data for the first time in foreign exchange.

We do, indeed, find that regions make a difference in the price impact of orders. Orders from the center regions tend to move prices permanently, i.e. they provide information. Orders from other regions, however, move prices for a few minutes only before they reverse to their former level.

Local information is so important, according to our analysis, that it even dominates conventional wisdom regarding preferred order type. Earlier studies have argued forcefully that informed traders prefer market orders and the uninformed tend to rely on limit orders (see the excellent discus- 
sion in Bloomfield, O'Hara and Saar, 2005). Consequently, the former have price impact and the latter have not. In a novel analysis we break down this simplified distinction of two cases - market versus limit orders - into six cases, i.e. three types of orders times two types of traders, either from center regions or others. Due to this disaggregation we find that location "beats" order type. Market orders and aggressively-priced limit orders of center traders are informative whereas orders from other regions are on average never informative, whatever order type they choose.

This evidence cannot be easily explained by different order size as we measure the price impact per dollar. The finding is also robust to various market conditions. Moreover, we control for possible effects of common news shocks and feedback trading which might both drive results, as has been argued recently. However, findings are robust and also hold for different aggregation of trading data or splits of the overall sample.

Finally, concerns might refer to the Russian RUR/USD market, which is small compared to world leading markets. This lower transaction volume, however, basically seems to reflect the smaller size of the Russian economy and does not necessarily lead to different market statistics. Moreover, the Russian foreign exchange market uses a very similar trading technology to other leading electronic currency markets. Nevertheless, we have conducted standard tests on market behavior to see whether this market might be different; results confirm market characteristics of leading markets as examined for example by Payne (2003).

Therefore, findings may be seen as an extension of earlier price impact analyses: we split aggregate order flow according to regions and in a further step even consider aggressively priced limit orders. Whatever analysis is performed, order flows from the center regions tend to be informed and order flows originating from other regions are not - providing strong evidence in favor of local information in foreign exchange markets. 


\section{References}

Bae, Kee-Hong, René Stulz and Hongpin Tan, 2005. Do local analysts know more? A cross-country study of the performance of local analysts and foreign analysts. NBER Working Paper 11697.

Berger, Helge, Michael Ehrmann and Marcel Fratzscher, 2006. Forecasting ECB monetary policy accuracy is (still) a matter of geography. ECB Working Paper 578.

BIS, 2002. Triennial central bank survey of foreign exchange and derivatives market activity in 2001. Basle.

Bjønnes, Geir H. and Dagfinn Rime, 2005. Dealer behavior and trading systems in foreign exchange markets. Journal of Financial Economics, 75:3, 571-605.

Bloomfield, Robert, Maureen O'Hara and Gideon Saar, 2005. The "make or take" decision in an electronic market: evidence on the evolution of liquidity. Journal of Financial Economics 75, 165-199.

Brandt, Michael W. and Kenneth A. Kavajecz, 2004. Price discovery in the U.S. treasury market: the impact of order flow and liquidity on the yield curve. Journal of Finance 59:6, 2623-2654.

Breedon, Francis and Paolo Vitale, 2005. An empirical study of liquidity and information effects of order flow on exchange rates. CEPR Discussion Paper 4586.

Campbell, John Y., Tarun Ramadorai and Tuomo Vuolteenaho, 2005. Caught on tape: institutional order flow and stock returns. NBER Working Paper 11439.

Cheung, Yin-Wong and Clement Yuk-Pang Wong, 2000. A survey of market practitioners' views on exchange rate dynamics. Journal of International Economics 51, 401-419.

Chung, Kee H., Bonnie F. Van Ness and Robert A. Van Ness, 1999. Limit orders and the bid-ask spread. Journal of Financial Economics, 53, 255-287.

Clark, Peter K., 1973. A subordinated stochastic process model with finite variance for speculative prices. Econometrica 41:1, 135-155.

Coval, Joshua D. and Tobias J. Moskowitz, 2001. The geography of investment: informed trading and asset prices. Journal of Political Economy 109:4, 811-841.

Covrig, Vicentiu and Michael Melvin, 2002. Asymmetric information and price discovery in the FX market: does Tokyo know more about the yen?. Journal of Empirical Finance 9, 271-285.

Daníelsson, Jón and Richard Payne, 2002. Real trading patterns and prices in spot foreign exchange markets. Journal of International Money and Finance, 21:2, 203-222.

Daníelsson, Jón and Ryan Love, 2006. Feedback trading. International Journal of Finance and Economics, 11:1, 35-53.

De Jong, Frank, Ronald Mahieu, Peter Schotman and Irma van Leuwen, 2001. Price discovery on foreign exchange markets with differentially informed traders. CEPR Discussion Paper 2296.

Dominguez, Kathry M.E., 2003. The market microstructure of central bank intervention. Journal of International Economics 59, 25-45.

Dominguez, Kathryn M.E. and Freyan Panthaki, 2006. What defines "news" in foreign exchange markets?. Journal of International Money and Finance, forthcoming.

Dufour, Alfonso and Robert F. Engle, 2001. Time and the price impact of a trade. Journal of Finance, $55: 6,2467-2498$.

Easley, David and Maureen O'Hara, 1987. Price, trade size and information in securities markets. Journal of Financial Economics 19, 69-90.

Evans, Martin D., 2002. FX trading and exchange rate dynamics. Journal of Finance 57:6, 2405-2447.

Evans, Martin D. and Richard K. Lyons, 2002. Order flow and exchange rate dynamics. Journal of Political Economy, 110, 170-180.

Evans, Martin D. and Richard K. Lyons, 2003. How is macro news transmitted to exchange rates?. NBER Working Paper 9433.

Evans, Martin D. and Richard K. Lyons, 2005. Exchange rate fundamentals and order flow. Working Paper, Haas School of Business, U.C. Berkeley.

Foster, Douglas F. and S. Viswanathan, 1990. A theory of the interday variations in volume, variance, and trading costs in securities markets. Review of Financial Studies 3:4, 593-624. 
Frankel, Jeffrey and Andrew Rose, 1995. Empirical research on nominal exchange rates. in: Gene Grossmann and Kenneth Rogoff (eds.), Handbook of International Economics Vol. III. Amsterdam et al.: North-Holland, 1689-1729.

Gehrig, Thomas and Lukas Menkhoff, 2004. The use of flow analysis in foreign exchange: exploratory evidence. Journal of International Money and Finance 23, 573-594.

Goldberg, Linda S. and Rafael Tenorio, 1997. Strategic trading in a two-sided foreign exchange auction. Journal of International Economics 42, 299-326.

Hasbrouck, Joel, 1991. Measuring the information content of stock trades. Journal of Finance 46:1, 179-207.

Hasbrouck, Joel, 2006. Empirical market microstructure. Oxford et al.: Oxford University Press.

Hasbrouck, Joel and Gideon Saar, 2004. Technology and liquidity provision: the blurring of traditional definitions. Working Paper, Stern School of Business, New York University.

Hau, Harald, 2001. Location matters: an examination of trading profits. Journal of Finance 56:3, 19591983.

Huberman, Gur, 2001. Familiarity breeds investment. Review of Financial Studies 14:3, 659-680.

Ivković, Zoran and Scott Weisbenner, 2005. Local does as local is: information content of the geography of individual investors' common stock investments. Journal of Finance 60:1, 267306.

Ito, Takatoshi, Richard K. Lyons and Michael T. Melvin, 1998. Is there private information in the FX market? The Tokyo experiment. Journal of Finance 53:3, 1111-1130.

Kaniel, Ron and Hong Liu, 2004. So what orders do informed traders use?. Journal of Business, forthcoming.

Killeen, William P., Richard K. Lyons and Michael Moore, 2006. Fixed versus flexible: lessons from EMS order flow. Journal of International Money and Finance, forthcoming.

Lütkepohl, Helmut, 2005. New introduction to multiple time series analysis. Berlin et al.: Springer.

Lyons, Richard K., 1997. A simultaneous trade model of the foreign exchange hot potato. Journal of International Economics 42, 278-298.

Lyons, Richard K., 2001. The microstructure approach to exchange rates. Cambridge: MIT Press.

Malloy, Christopher, 2005. The geography of equity analysis. Journal of Finance 60:2, 719-756.

Marsh, Ian W. and Ceire O'Rourke, 2005. Customer order flow and exchange rate movements: is there really information content?. Working Paper, Cass Business School, London.

Meese, Richard and Kenneth Rogoff, 1983. Empirical exchange rate models of the seventies: do they fit out of sample?. Journal of International Economics 14, 3-24.

Osler, Carol L., 2003. Currency orders and exchange-rate dynamics: an explanation for the predictive success of technical analysis. Journal of Finance 58, 1791-1819.

Osler, Carol, Mende, Alexander and Lukas Menkhoff, 2006. Price discovery in currency markets. Working Paper, Brandeis University.

Payne, Richard, 2003. Informed trade in spot foreign exchange markets: an empirical investigation. Journal of International Economics 61, 307-329.

Peiers, Bettina, 1997. Informed traders, intervention, and price leadership: a deeper view of the microstructure of the foreign exchange market. Journal of Finance 52:4, 1589-1614.

Pesaran, H. Hashem and Yongcheol Shin, 1998. Generalized impulse response analysis in linear multivariate models. Economics Letters 58, 17-29.

Portes, Richard and Hélène Rey, 2005. The determinants of cross-border equity flows. Journal of International Economics 65, 269-296.

Sapp, Stephen, 2002. Price leadership in spot foreign exchange markets. Journal of Financial and Quantitative Analysis 37, 425-448.

Sarno, Lucio and Mark P. Taylor, 2002. The economics of exchange rates. Cambridge et al.: Cambridge University Press. 
Figure 1. RUR/USD spot exchange rate

This figure shows the evolution of the spot RUR/USD (vertical axis) over the nine trading days of our sample. The figure is based on midquotes in event time (all trades).

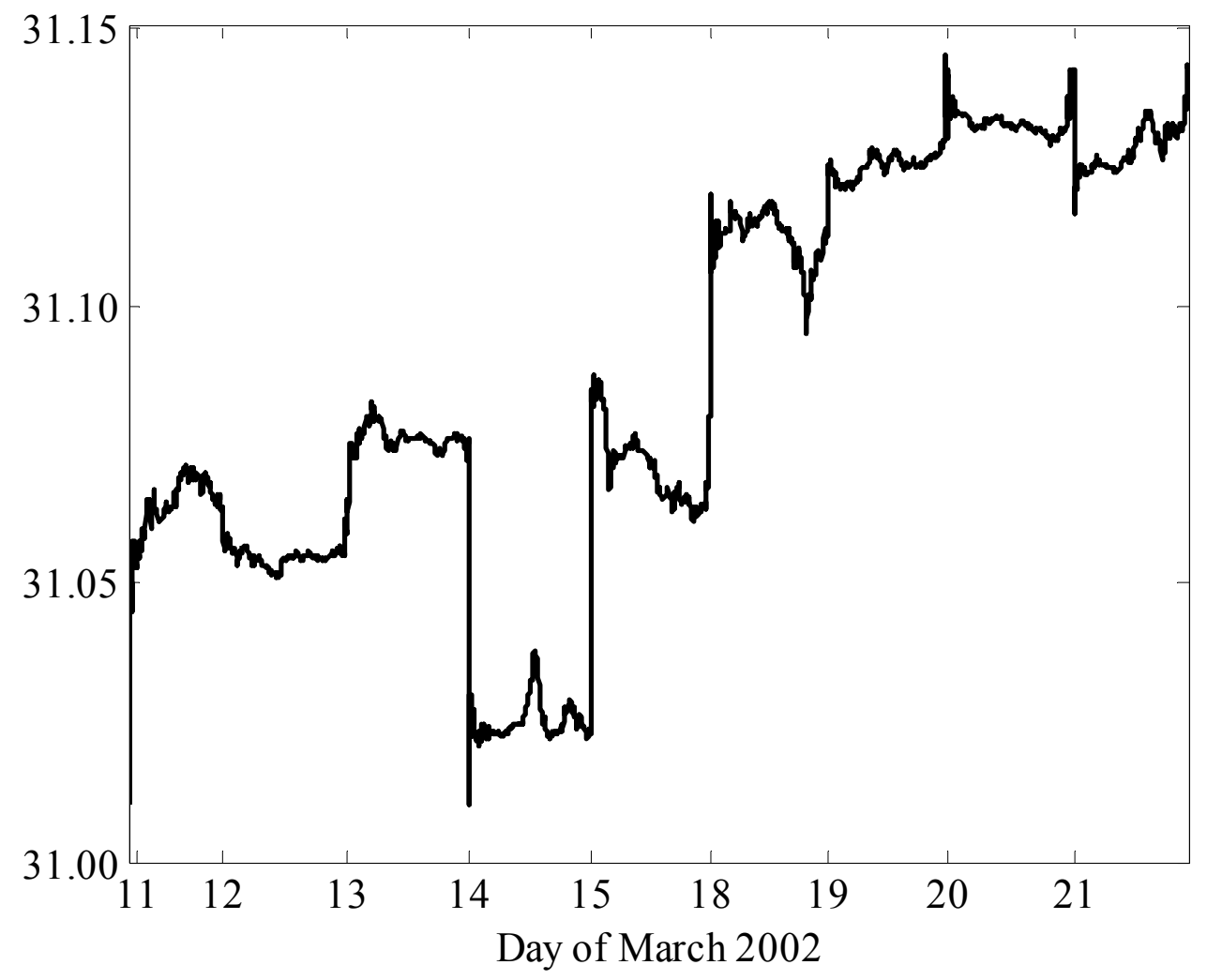


Table 1. Summary descriptive statistics for SELT order book and return data

Panel A of the table gives descriptive statistics for order book data. Column Min. gives the 5 minute sub sample, $\mathrm{Q}_{\mathrm{a}}$ and $\mathrm{Q}_{\mathrm{b}}$ show ask and bid volume in $\$ \mathrm{~m}$ outstanding. Similarly Asks and Bids show the number of ask and bid orders queued in the order book. The next column "spread" shows the average percentage spread. $\overline{\mathrm{LO}}(\overline{\mathrm{MO}})$ and $\Sigma \mathrm{LO}(\Sigma \mathrm{MO})$ show the average and total trading volume in mill. USD of limit (market) orders. Panel B shows basic statistics for midquote returns (in pips). The first four columns show the first four sample moments of the return series. Columns headed $\rho_{-1}, \mathrm{Q}^{(5)}$ and $\mathrm{Q}^{2}(5)$ give the first order autocorrelations, fifth order Ljung-Box test statistics for returns and fifth order Ljung-Box test statistics for squared residual returns respectively. Note that residual returns are calculated by using an MA(1)-Model for returns. The critical values for the test statistics in the seventh and eighth column are 11.07 and 15.09 respectively.

Panel A: Order book statistics

\begin{tabular}{|c|c|c|c|c|c|c|c|c|c|c|}
\hline 10 & 5903 & 11.04 & 11.86 & 106.52 & 97.88 & 0.0114 & 0.0894 & 211.00 & 0.0522 & 126.00 \\
\hline 20 & 3509 & 7.45 & 10.32 & 86.68 & 102.02 & 0.0044 & 0.0882 & 128.00 & 0.0474 & 58.82 \\
\hline 25 & 2745 & 7.09 & 8.61 & 95.66 & 88.27 & 0.0049 & 0.0903 & 97.36 & 0.0468 & 47.95 \\
\hline 30 & 2256 & 6.87 & 8.77 & 93.29 & 81.26 & 0.0049 & 0.1038 & 93.84 & 0.0392 & 32.61 \\
\hline 40 & 2154 & 4.87 & 8.52 & 82.78 & 69.78 & 0.0051 & 0.1040 & 83.10 & 0.0500 & 38.00 \\
\hline 45 & 1769 & 3.61 & 7.93 & 68.62 & 71.08 & 0.0048 & 0.0737 & 51.21 & 0.0514 & 30.70 \\
\hline 50 & 1653 & 2.91 & 7.63 & 58.79 & 70.91 & 0.0046 & 0.0843 & 50.11 & 0.0427 & 23.12 \\
\hline 55 & 1574 & 1.93 & 8.24 & 39.34 & 63.06 & 0.0045 & 0.1078 & 57.01 & 0.0399 & 23.18 \\
\hline 60 & 1541 & 1.95 & 8.26 & 23.58 & 51.43 & 0.0060 & 0.1105 & 58.34 & 0.0444 & 22.04 \\
\hline
\end{tabular}

Panel B: Return statistics

\begin{tabular}{crrrrrrr}
\hline Min. & \multicolumn{1}{c}{ Mean } & \multicolumn{1}{c}{ Var. } & \multicolumn{1}{c}{ Skew. } & \multicolumn{1}{c}{ Kurt. } & $\rho_{-1}$ & Q(5) & $\mathrm{Q}^{2}(5)$ \\
\hline 5 & 0.3520 & 24.9184 & 5.1387 & 168.6030 & -0.1939 & 126.46 & 86.90 \\
10 & -0.0250 & 4.0390 & -0.9981 & 58.9012 & -0.2778 & 200.09 & 124.45 \\
15 & 0.1300 & 3.1008 & -0.3600 & 29.1595 & -0.2324 & 108.11 & 52.57 \\
20 & -0.0620 & 5.4197 & 0.6199 & 32.7976 & -0.2771 & 120.29 & 195.58 \\
25 & -0.1338 & 4.1408 & 0.7347 & 27.5155 & -0.1988 & 59.28 & 121.71 \\
30 & -0.1442 & 4.2614 & 0.6517 & 32.2278 & -0.1450 & 57.92 & 115.58 \\
35 & 0.1043 & 4.0087 & 0.2024 & 19.9866 & -0.1852 & 31.87 & 102.93 \\
40 & 0.0092 & 5.7416 & 0.5517 & 51.3059 & -0.2712 & 79.15 & 239.22 \\
45 & -0.0787 & 3.4352 & -0.5075 & 20.5200 & -0.1315 & 16.86 & 77.25 \\
50 & 0.1017 & 3.2788 & -1.0582 & 19.1347 & -0.0170 & 44.27 & 38.08 \\
55 & 0.4355 & 4.9111 & 2.3719 & 52.1263 & -0.0923 & 6.85 & 3.48 \\
60 & 0.3266 & 12.3240 & 0.7148 & 25.8205 & -0.2652 & 28.45 & 23.91 \\
\hline
\end{tabular}


Table 2. Regional characteristics

This table shows aggregate data for eight regions represented by traders in our sample. All data used in this table come from the "Analytical System of Economic Activities" provided by the Russian central bank. For all numbers below we use average quarterly values for the period April 1, 2001 to March 31, 2002. The respective headings stand for the number of banks operating in the region (\# Banks), the volume of foreign currency accounts (FCAV) in $\mathrm{m}$ USD, the profits in mill. RUR earned by these banks, the debt investments (DI) in mill. RUR in local bank portfolios, the equity investments (EI) in $\mathrm{m}$. RUR in local bank portfolios, and industrial production (IP) in mill. RUR. The fifth and sixth columns shows foreign currency account volume per number of local banks and as a share of industrial production, column ten gives profits per number of local banks, and the last two columns report debt and equity investments as share of industrial production.

\begin{tabular}{|c|c|c|c|c|c|c|c|c|c|c|c|}
\hline Region & \# Banks & FCAV & IP & $\begin{array}{l}\text { FCAV/ } \\
\text { \# Banks }\end{array}$ & $\begin{array}{c}\mathrm{FCAV} / \\
\text { IP }\end{array}$ & Profits & DI & EI & $\begin{array}{l}\text { Profits/ } \\
\text { \# Banks }\end{array}$ & $\mathrm{DI} / \mathrm{IP}$ & EI / IP \\
\hline Moscow & 595 & 70,506 & 155,652 & 118.50 & $45.30 \%$ & $24,937.56$ & 31,163 & 358,022 & $41,911.86$ & $20.02 \%$ & $230.01 \%$ \\
\hline St. Petersburg & 40 & 4,262 & 83,730 & 106.54 & $5.09 \%$ & 531.32 & 570 & 9,783 & $13,280.58$ & $0.68 \%$ & $11.68 \%$ \\
\hline Ekaterinburg & 28 & 295 & 111,986 & 10.53 & $0.26 \%$ & 95.26 & 101 & 1,415 & $3,402.11$ & $0.09 \%$ & $1.26 \%$ \\
\hline Rostov & 24 & 53 & 42,330 & 2.22 & $0.13 \%$ & 25.35 & 52 & 57 & $1,056.38$ & $0.12 \%$ & $0.13 \%$ \\
\hline Samara & 22 & 556 & 96,152 & 25.27 & $0.58 \%$ & 119.41 & 219 & 719 & 543.05 & $0.23 \%$ & $0.75 \%$ \\
\hline N. Novgorod & 20 & 233 & 66,239 & 11.63 & $0.35 \%$ & 73.73 & 54 & 423 & $3,686.65$ & $0.08 \%$ & $0.64 \%$ \\
\hline Novosibirsk & 13 & 75 & 25,849 & 5.74 & $0.29 \%$ & 39.26 & 29 & 251 & $3,020.15$ & $0.11 \%$ & $0.97 \%$ \\
\hline Vladivostock & 6 & 89 & 34,912 & 14.80 & $0.25 \%$ & 37.79 & 4 & 74 & $6,298.83$ & $0.01 \%$ & $0.21 \%$ \\
\hline
\end{tabular}




\section{Table 3. Descriptive statistics for different regional trader groups}

This table shows trading statistics for C-traders and NC-traders traders as well as traders belonging to Moscow and St. Petersburg, respectively. Row Headings are as follows: \# Traders shows the number of traders belonging to the respective group, MO means market order, APL refers to aggressively priced limit orders submitted by the respective, OLO are submitted ordinary limit orders. The suffix "vol." means total volume over the nine trading days, whereas "\#" indicates the total number of observations belonging to the respective trading activity. All volumes are in mill. USD. Profits refer to trading profits from position and spread trading in mill. USD. Panel A shows aggregated values over the sample and Panel B shows the same trading statistics averaged over the number of traders belonging to each group.

Panel A: Trading statistics aggregated over the sample

\begin{tabular}{lrr:rr}
\hline & C-traders & NC-traders & Moscow & St. Petersburg \\
\hline \# Traders & 461 & 261 & 341 & 120 \\
MO vol. & 568.00 & 129.00 & 483.00 & 85.16 \\
MO \# & 10,476 & 3,633 & 8,089 & 2,387 \\
APL vol. & 202.00 & 53.70 & 170.00 & 31.69 \\
APL \#. & 2,072 & 1,325 & 1,647 & 425 \\
OLO vol. & 1120.00 & 257.00 & 928.00 & 188.00 \\
OLO \# & 7,611 & 4,951 & 5,483 & 2,128 \\
Profits & 1.97 & -1.97 & 1.71 & 0.26 \\
\hline
\end{tabular}

Panel B: Trading statistics per traders

\begin{tabular}{lrr:rr}
\hline & C-traders & NC-traders & Moscow & St. Petersburg \\
\hline MO vol. & 1.23 & 0.49 & 1.42 & 0.71 \\
MO \# & 22.72 & 13.92 & 23.72 & 19.89 \\
APL vol. & 0.44 & 0.21 & 0.50 & 0.26 \\
APL \#. & 4.49 & 5.08 & 4.83 & 3.54 \\
OLO vol. & 2.43 & 0.98 & 2.72 & 1.57 \\
OLO \# & 16.51 & 18.97 & 16.08 & 17.73 \\
Profits & 0.0043 & -0.0076 & 0.0050 & 0.0022 \\
\hline
\end{tabular}




\section{Figure 2. Cumulative generalized impulse-response function}

This figure shows cumulative generalized impulse responses of midquote returns to a one standard deviation shock in one of the four order flow measures. Calculations are based on the reduced form VAR in equation (2). Dashed lines show 95\% confidence intervals based on a bootstrap with 200 replications.
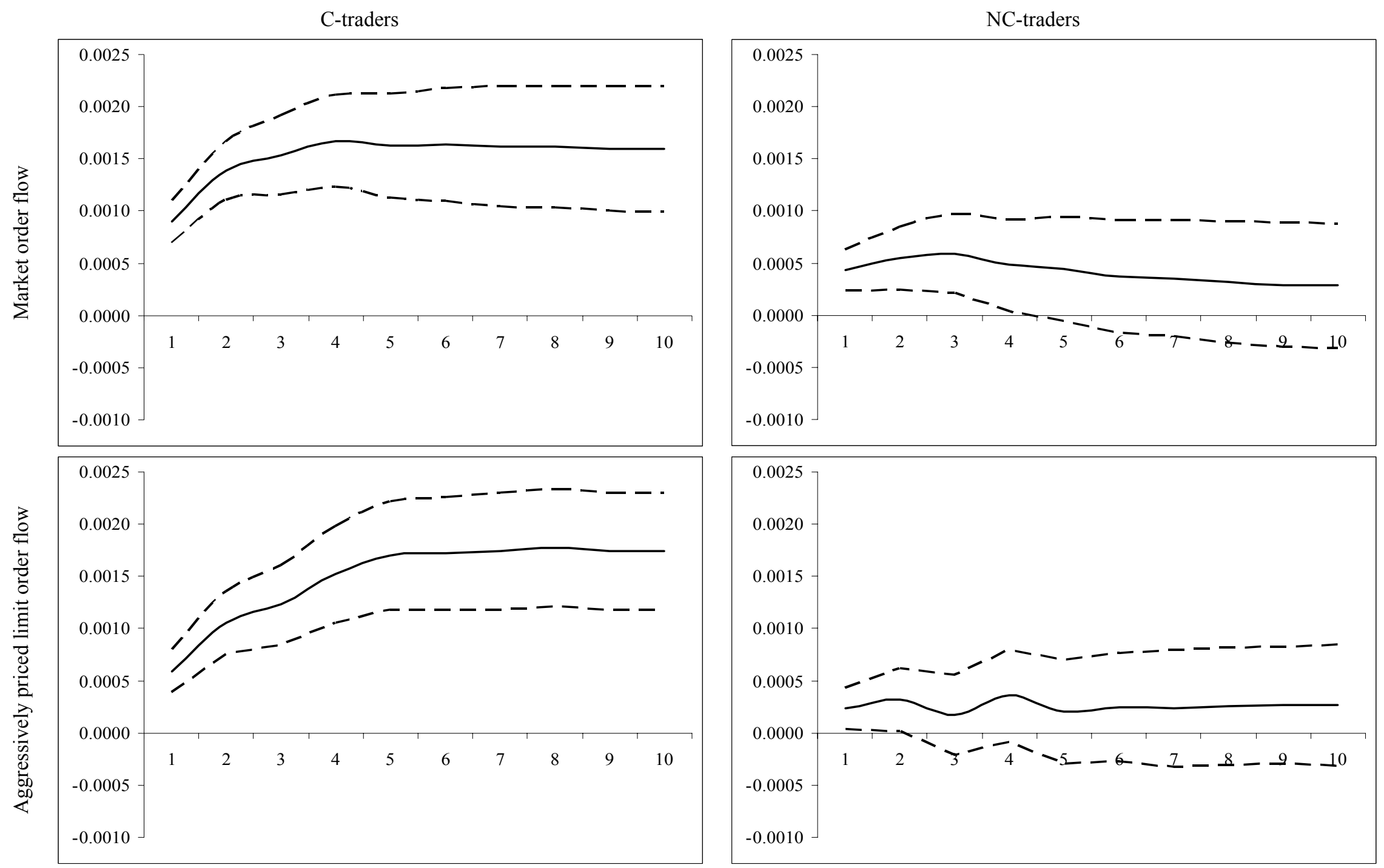


\section{Table 4. VAR analysis results}

This table shows estimation results for the reduced form VAR from equation (2). Panel A shows long-run cumulative impulse-responses based on generalized impulse-response functions for the whole sample (row "160 ") and for four sub samples consisting of the first fifteen minutes of all trading days, minutes 16-30, and so on. Numbers in parentheses are standard errors based on a bootstrap with 200 replications. Column AC shows the test statistic and p-value (in parentheses) of the LM test for autocorrelation up to the tenth lag. Panel B shows residual correlation of the reduced form VAR estimated over the whole sample. Stars refer to the level of significance $(* *: \alpha \leq 0.01, \alpha \leq 0.05)$.

Panel A: Cumulative responses

\begin{tabular}{|c|c|c|c|c|c|c|c|}
\hline \multirow[b]{2}{*}{ Minute } & \multicolumn{4}{|c|}{ Long-run cumulative response of midquote returns to shocks in } & \multirow[b]{2}{*}{ adj. $R^{2}$} & \multirow[b]{2}{*}{$\mathrm{AC}$} & \multirow[b]{2}{*}{ lags } \\
\hline & $\mathrm{x}^{\mathrm{C}}$ & $\mathrm{x}^{\mathrm{NC}}$ & $\mathrm{s}^{\mathrm{C}}$ & $\mathrm{s}^{\mathrm{NC}}$ & & & \\
\hline $1-60$ & $\begin{array}{r}0.0016 \\
* *(0.0003)\end{array}$ & $\begin{array}{r}0.0003 \\
(0.0003)\end{array}$ & $\begin{array}{r}0.0017 \\
* *(0.0003)\end{array}$ & $\begin{array}{r}0.0003 \\
(0.0003)\end{array}$ & $9.93 \%$ & $\begin{array}{l}24.69 \\
(0.48)\end{array}$ & 4 \\
\hline $1-15$ & $\begin{array}{r}0.0013 \\
* *(0.0006)\end{array}$ & $\begin{array}{r}0.0009 \\
(0.0007)\end{array}$ & $\begin{array}{r}0.0016 \\
* *(0.0005)\end{array}$ & $\begin{array}{r}-0.0002 \\
(0.0006)\end{array}$ & $20.19 \%$ & $\begin{array}{r}18.98 \\
(0.80)\end{array}$ & 4 \\
\hline $16-30$ & $\begin{array}{r}0.0020 \\
* *(0.0007)\end{array}$ & $\begin{array}{r}0.0004 \\
(0.0006)\end{array}$ & $\begin{array}{r}0.0015 \\
* *(0.0007)\end{array}$ & $\begin{array}{r}-0.0002 \\
(0.0006)\end{array}$ & $8.02 \%$ & $\begin{array}{r}27.37 \\
(0.34)\end{array}$ & 9 \\
\hline $31-45$ & $\begin{array}{r}0.0016 \\
* *(0.0004)\end{array}$ & $\begin{array}{r}0.0004 \\
(0.0005)\end{array}$ & $\begin{array}{r}0.0006 \\
*(0.0003)\end{array}$ & $\begin{array}{r}0.0004 \\
(0.0003)\end{array}$ & $12.31 \%$ & $\begin{array}{l}21.65 \\
(0.66)\end{array}$ & 3 \\
\hline $45-60$ & $\begin{array}{r}0.0018 \\
*(0.0009)\end{array}$ & $\begin{array}{r}0.0009 \\
(0.0009)\end{array}$ & $\begin{array}{r}0.0028 \\
* *(0.0012)\end{array}$ & $\begin{array}{r}0.0003 \\
(0.0009)\end{array}$ & $14.71 \%$ & $\begin{array}{c}22.36 \\
(0.61)\end{array}$ & 5 \\
\hline
\end{tabular}

Panel B: Residual correlation

\begin{tabular}{lrrrrr}
\hline & $\mathrm{r}$ & \multicolumn{1}{c}{$\mathrm{x}^{\mathrm{C}}$} & \multicolumn{1}{c}{$\mathrm{x}^{\mathrm{NC}}$} & \multicolumn{1}{c}{$\mathrm{s}^{\mathrm{C}}$} & \multicolumn{1}{c}{$\mathrm{s}^{\mathrm{NC}}$} \\
\hline $\mathrm{r}$ & & 0.28 & 0.13 & 0.18 & 0.07 \\
$\mathrm{x}^{\mathrm{C}}$ & $* *(0.00)$ & & 0.11 & 0.05 & -0.04 \\
$\mathrm{x}^{\mathrm{NC}}$ & $* *(0.00)$ & $* *(0.00)$ & & 0.01 & -0.03 \\
$\mathrm{~s}^{\mathrm{C}}$ & $* *(0.00)$ & $(0.11)$ & $(0.72)$ & & -0.03 \\
$\mathrm{~s}^{\mathrm{NC}}$ & $*(0.02)$ & $(0.17)$ & $(0.27)$ & $(0.29)$ & \\
\hline
\end{tabular}




\section{Figure 3. Price impacts under different market conditions}

This figure plots price impact of market orders (black bars) and price aggressive limit orders (grey bar) by Ctraders under different market conditions, separated by dashed lines. The price impacts are estimated by reduced form VARs as detailed in equation (2). The first two bars show price impacts for the whole sample as shown in Table 4. The next three sections show impacts for high and low trading volume (TV), high and low book volume (BV) and high and low spreads. Trading volume is defined as the total volume traded in each 30 second interval, book volume is the average size of the order book per interval and spreads are computed as median values for each interval. The median of these variables serves to split the sample into sub samples of high and low realizations.

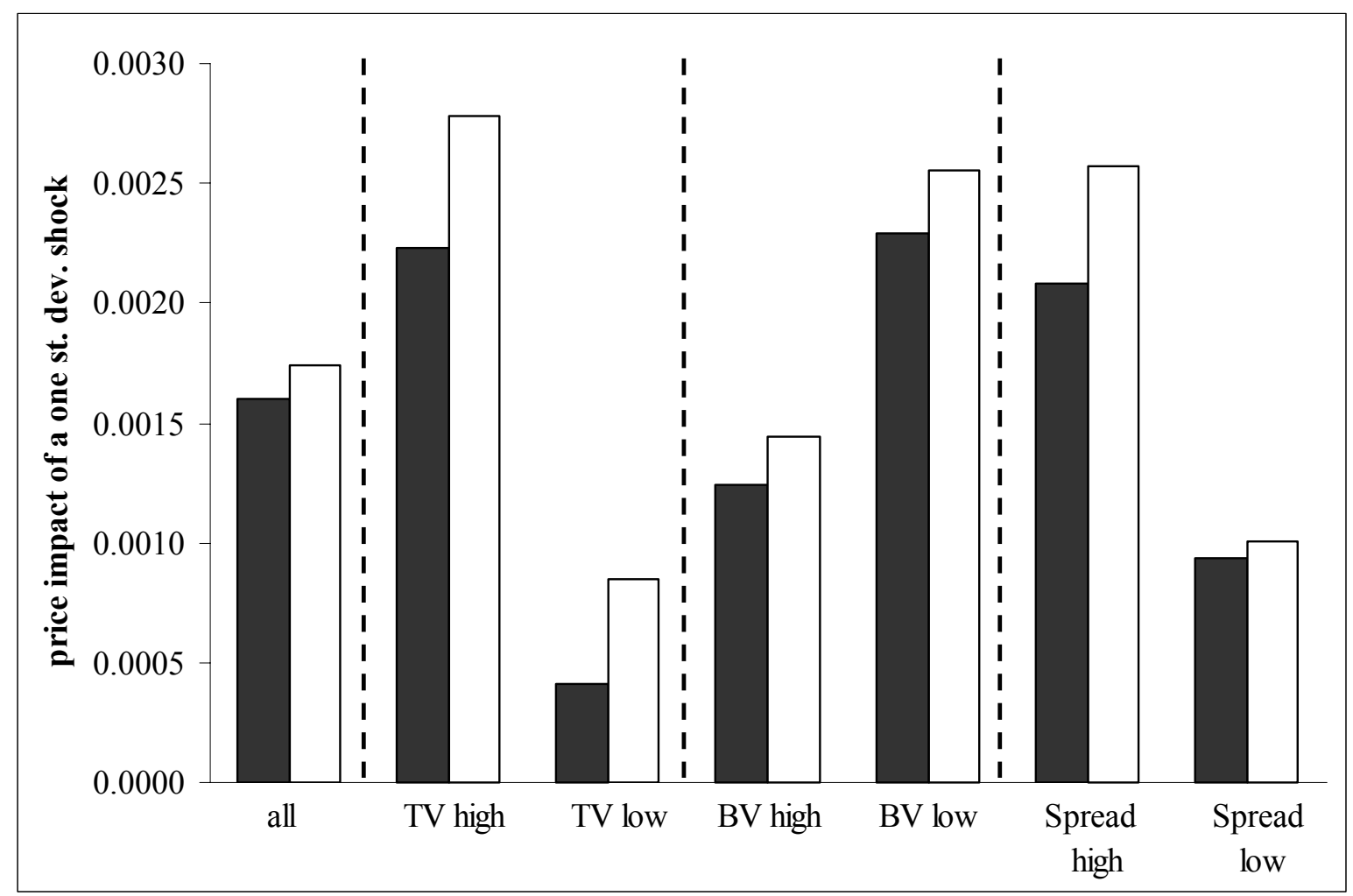




\section{Figure 4. Cumulative impulse-responses from the SVAR with common news shocks}

This figure shows cumulative impulse responses of midquote returns to a one standard deviation shock in one of the four order flow measures. Calculations are based on the structural VAR in equations (4a) and (4b). Dashed lines show 95\% confidence intervals based on a bootstrap with 200 replications.
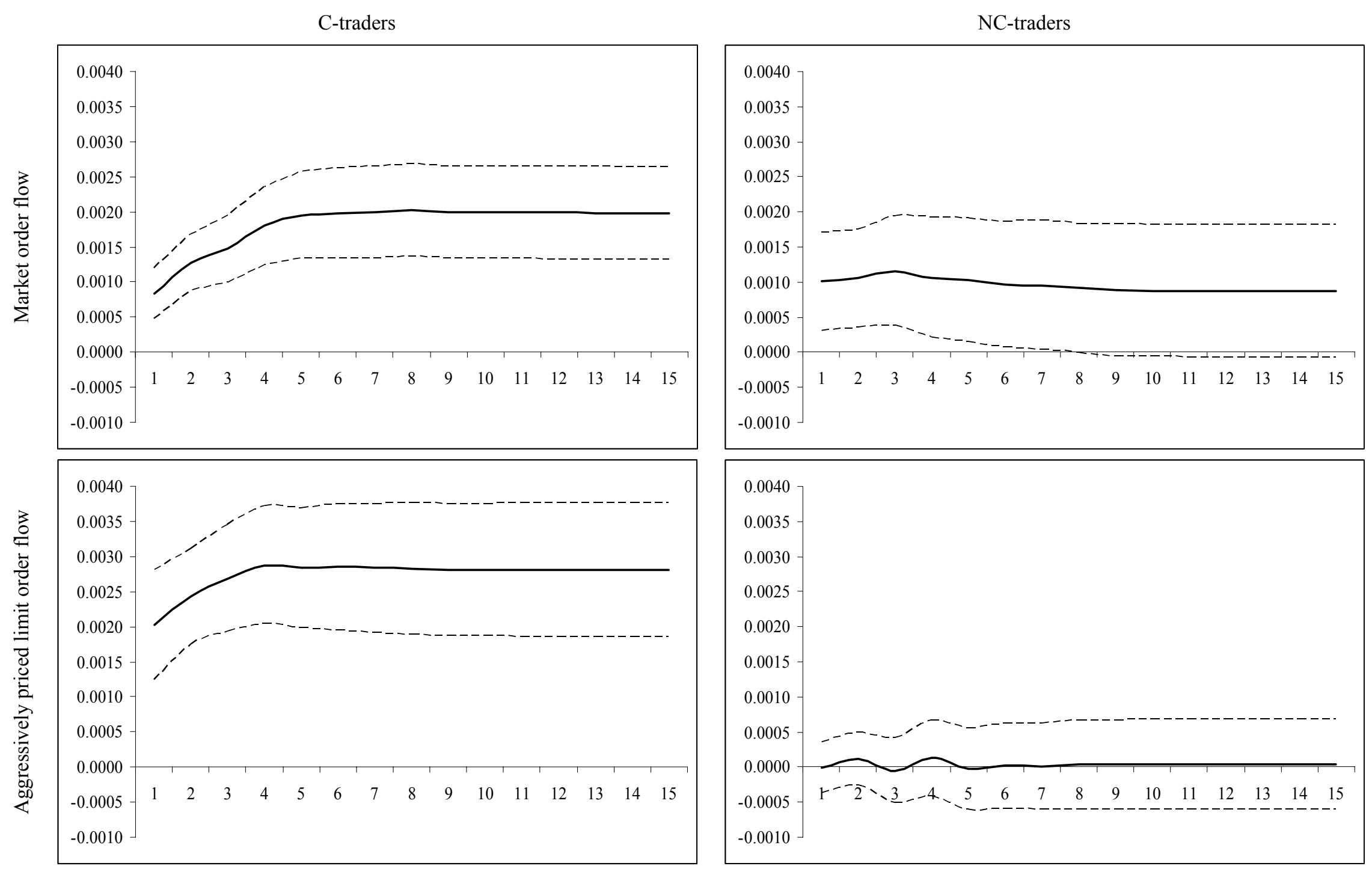


\section{Table 5. Structural VAR analysis results}

This table shows estimation results for the structural VAR in equations (4) and (5). In Panel A, the first row $\left(\Sigma \gamma_{i}\right)$ shows the sum of lagged price impact coefficients, e.g. the sum of all lags of C-traders' market order flow $\mathrm{x}^{\mathrm{C}}$ in the midquote return equation in column " $\mathrm{x}^{\mathrm{C}}$. The second row $(\mathrm{CR})$ shows cumulative long-run responses of midquote returns to a one standard deviation structural shocks in the respective variable shown in the column, whereas the third row $(\operatorname{VD}(15))$ shows the variance decomposition for a horizon of 15 periods, i.e. 7.5 minutes. The next row $\left(\alpha^{\mathrm{i}}\right)$ shows the contemporaneous price impact coefficient estimates whereas the next row $\left(\delta^{i}\right)$ shows the estimated coefficients for the spillover from return shocks to order flows. In the last row, $\chi(2)$ denotes the test statistic for over-identification in the SVAR with two dof, AC(10) shows the LM test for autocorrelation at lag 10 and obs are the number of observations included in the estimation. Numbers in parentheses denote (bootstrap-based) standard errors for the first two rows, t-statistics for the rows $\alpha^{\mathrm{i}}$ and $\delta^{\mathrm{i}}$ and $\mathrm{p}$-values in the last row. Stars refer to the level of significance $(* *: \alpha \leq 0.01, \alpha \leq 0.05)$. The same applies to Panel B, for the SVAR with common news shocks and feedback trading, except for the fact that $\psi^{\mathrm{i}}$ denotes the feedback from returns to C-traders' order flows.

Panel A: Common news shocks

\begin{tabular}{|c|c|c|c|c|c|}
\hline & $\mathrm{r}$ & $x^{C}$ & $\mathrm{x}^{\mathrm{NC}}$ & $\mathrm{s}^{\mathrm{C}}$ & $\mathrm{s}^{\mathrm{NC}}$ \\
\hline$\Sigma \gamma_{\mathrm{i}}$ & $\begin{array}{r}0.1173 \\
(0.0576)\end{array}$ & $\begin{array}{r}0.0001 \\
* *(0.0000)\end{array}$ & $\begin{array}{r}-0.0001 \\
(0.0001)\end{array}$ & $\begin{array}{r}0.0003 \\
* *(0.0001)\end{array}$ & $\begin{array}{r}-0.0000 \\
(0.0002)\end{array}$ \\
\hline CR & $\begin{array}{r}0.0022 \\
* *(0.0008)\end{array}$ & $\begin{array}{r}0.0028 \\
* *(0.0005)\end{array}$ & $\begin{array}{r}0.0009 \\
(0.0005)\end{array}$ & $\begin{array}{r}0.0020 \\
* *(0.0003)\end{array}$ & $\begin{array}{r}0.0000 \\
(0.0003)\end{array}$ \\
\hline $\mathrm{VD}(15)$ & $42.81 \%$ & $37.86 \%$ & $9.08 \%$ & $9.41 \%$ & $0.85 \%$ \\
\hline$\alpha^{i}\left(\times 10^{3}\right)$ & & $\begin{array}{r}0.3451 \\
* *(2.72)\end{array}$ & $\begin{array}{r}0.6762 \\
* *(2.52)\end{array}$ & $\begin{array}{r}0.2689 \\
* *(3.85)\end{array}$ & $\begin{array}{r}0.0421 \\
(0.04)\end{array}$ \\
\hline$\delta^{\mathrm{i}}$ & & $\begin{array}{r}-2.7849 \\
*(-2.20) \\
\end{array}$ & $\begin{array}{l}-0.3772 \\
*(-2.13) \\
\end{array}$ & $\begin{array}{r}-0.3361 \\
(-1.55) \\
\end{array}$ & $\begin{array}{r}0.0953 \\
(1.63) \\
\end{array}$ \\
\hline obs & 1,440 & $\mathrm{AC}(10)$ & $\begin{array}{l}24.69 \\
(0.48)\end{array}$ & $\chi(2)$ & $\begin{array}{c}0.83 \\
(0.66)\end{array}$ \\
\hline
\end{tabular}

Panel B: Common news shocks and feedback trading

\begin{tabular}{lrrrrr}
\hline & $\mathrm{r}$ & \multicolumn{1}{c}{$\mathrm{x}^{\mathrm{C}}$} & \multicolumn{1}{c}{$\mathrm{x}^{\mathrm{NC}}$} & \multicolumn{1}{c}{$\mathrm{s}^{\mathrm{C}}$} & \multicolumn{1}{c}{$\mathrm{s}^{\mathrm{NC}}$} \\
\hline \multirow{2}{*}{$\mathrm{CR}$} & 0.0023 & 0.0021 & 0.0009 & 0.0027 & -0.0000 \\
& $(0.0013)$ & $* *(0.0009)$ & $(0.0005)$ & $* *(0.0008)$ & $(0.0004)$ \\
$\mathrm{VD}(15)$ & $47.02 \%$ & $20.98 \%$ & $9.36 \%$ & $21.72 \%$ & $0.92 \%$ \\
\hline \multirow{2}{*}{$\psi^{\mathrm{i}}$} & & 1.2524 & & -0.9726 & \\
& & $(1.71)$ & & $(-0.71)$ & \\
$\alpha^{\mathrm{i}}\left(\times 10^{3}\right)$ & & 0.2561 & 0.6950 & 0.4549 & 0.1041 \\
& & $*(1.99)$ & $* *(2.71)$ & $*(2.08)$ & $(0.26)$ \\
$\delta^{\mathrm{i}}$ & & -2.3975 & -0.3757 & -0.4473 & 0.1154 \\
& & $(-1.83)$ & $* *(-2.33)$ & $(-0.94)$ & $(1.41)$ \\
\hline \multirow{2}{*}{ obs } & \multirow{2}{*}{1,440} & $\mathrm{AC}(10)$ & 23.21 & & \\
\hline
\end{tabular}




\section{Appendix 1. Survival probabilities of aggressively and non-aggressively priced limit orders}

This table shows survival probabilities of differently priced limit orders separately for orders submitted by Ctraders (Panel A) and NC-traders (Panel B). Non-aggressively priced limit orders are priced outside the prevailing spread whereas aggressively priced limit (APL) orders are priced within the prevailing spread. Survival probabilities are calculated separately for orders that are executed (black lines) and for those cancelled before execution (thick grey lines).

\section{PANEL A: C-traders}



PANEL B: NC-traders

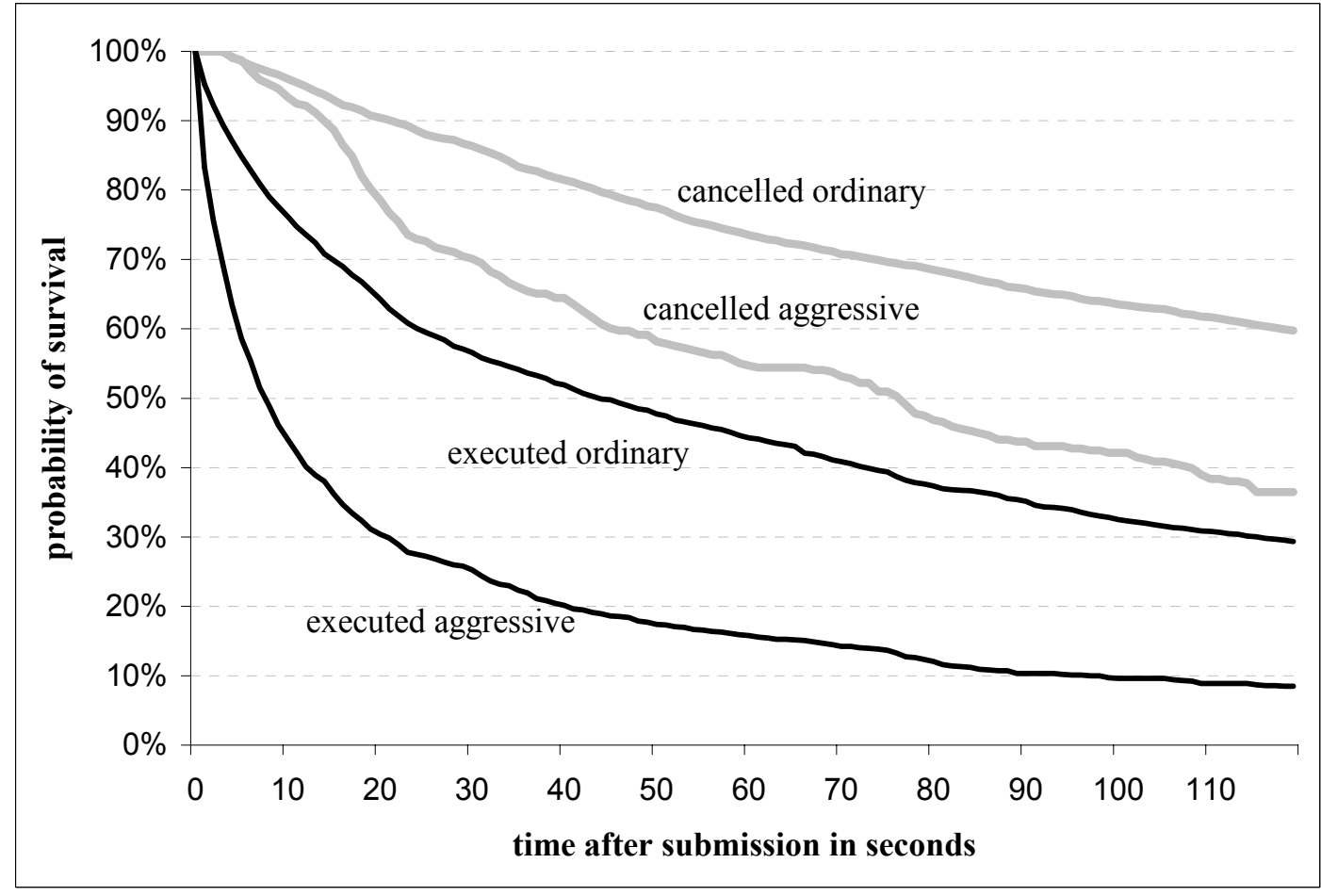




\section{Appendix 2. Bivariate SVAR results for midquote returns and market order flow}

This figure shows the cumulative impulse-response for midquote returns after a one standard deviation shock in market order flow. The corresponding SVAR follows Hasbrouck (1991) and Payne (2003) and contains midquote returns and market order flow only (five lags). The vertical axis shows the price impact in percent and the horizontal axis shows the forecast horizon.

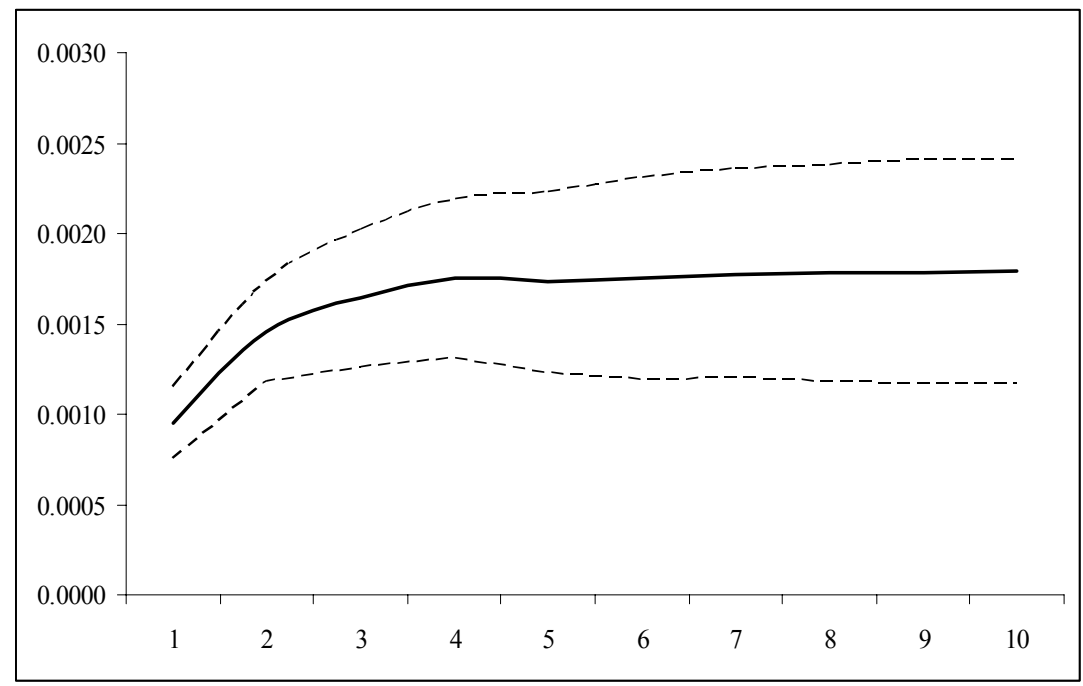

